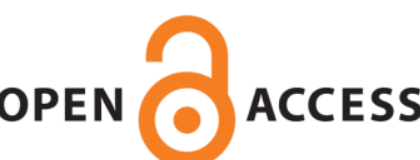

OPEN ACCESS

UWS Academic Portal

\title{
Failure to report poor care as a breach of moral and professional expectation
}

Ion, R.; Olivier, S. C.; Darbyshire, P.

Published in:

Nursing Inquiry

DOI:

10.1111/nin.12299

Published: 31/07/2019

Document Version

Peer reviewed version

Link to publication on the UWS Academic Portal

Citation for published version (APA):

Ion, R., Olivier, S. C., \& Darbyshire, P. (2019). Failure to report poor care as a breach of moral and professional expectation. Nursing Inquiry, 26(3), [e12299]. https://doi.org/10.1111/nin.12299

\section{General rights}

Copyright and moral rights for the publications made accessible in the UWS Academic Portal are retained by the authors and/or other copyright owners and it is a condition of accessing publications that users recognise and abide by the legal requirements associated with these rights. 
This is the peer reviewed version of the following article:

Ion, R, Olivier, S, Darbyshire, P. Failure to report poor care as a breach of moral and professional expectation. Nurs Inq. 2019; 26:e12299.

which has been published in final form at https://doi.org/10.1111/nin.12299. This article may be used for non-commercial purposes in accordance with Wiley Terms and Conditions for Use of Self-Archived Versions 
Failure to report as a breach of moral and professional expectation

\begin{abstract}
Cases of poor care have been documented across the world. Contrary to professional requirements, evidence indicates that these sometimes go unaddressed. For patients the outcomes of this inaction are invariably negative. Previous work has either focused on why poor care occurs and what might be done to prevent it, or on the reasons why those who are witness to it find it difficult to raise their concerns. Here we build on this work but specifically foreground the responsibilities of registrants and students who witness poor care. Acknowledging the challenges associated with raising concerns, we make the case that failure to address poor care is a breach of moral expectation, professional requirement and sometimes, legal frameworks. We argue that reporting will be more likely to take place if those who wish to enter the profession have a realistic view of the challenges they may encounter. When nurses are provided with robust and applied education on ethics, when 'real-world' cases and exemplars are used in practice and when steps are taken to develop and encourage individual moral courage, we may begin to see positive change. Ultimately however, significant change is only likely to take place where practice cultures invite and welcome feedback, promote critical reflection, and where strong, clear leadership support is shown by those in positions of influence across organisations.
\end{abstract}

\title{
Introduction
}

The issue of poor care has received considerable attention over the past few years. Much of this interest has focused on exploration of why it occurs and what might be done to prevent it. Stenhouse et al. (2016) provide an overview of these discussions, with Paley (2014), Randall and McKeown (2014), Roberts and Ion, (2014) and Bagnasco et al. (2017) among the many who have contributed more detailed accounts. An additional strand of work has examined the responses of those who witness poor care, with evidence suggesting that many choose not to 
Failure to report as a breach of moral and professional expectation

take action - reviews by Jackson et al. (2014) and Ion, Smith, and Dickens (2017) summarise much of this literature. In this paper we consider a related, but comparatively neglected issue - specifically the legal, moral and ethical position of those who witness poor care. In doing this we acknowledge and draw on the work of Skarlicki and Kulik (2004) whose detailed model provides a valuable framework for understanding the responses of those who witness unjust behaviour in the workplace. Taking account of a range of factors, including the characteristics of transgressors and witnesses, interpersonal relationships, as well as the perceived severity of the transgression and the likely response of organisations, they outline the interplay of factors which inform decisions about whether or not to take action when faced with perceived unfair, unjust, morally or ethically unacceptable behaviour. Here we deal with one element of this, namely the need to ensure that witnesses understand both their role and their responsibilities in relation to injustice. Without a clear understanding of this, it is unreasonable to expect that individuals will act in ways which may often have a negative impact upon them. We make the case that nurses are obligated to act to protect patients and clients and that failure to do so compromises patient safety. In doing this we acknowledge the challenges associated with speaking out and intervening, especially in toxic, hierarchical cultures (Darbyshire \& Thompson 2018), but argue that failure to do so privileges the needs of the nurse over those of the patient. Finally we suggest approaches which may be used to encourage action and promote responses that foreground the needs of patients and prioritise their safety and dignity.

\section{Defining the problem of poor care}


Failure to report as a breach of moral and professional expectation

Professional and ethical guidance from across the world makes it clear that nurses are expected to prioritise patients' welfare and ensure their safety (American Nurses Association, 2015, ICN, 2012, Nursing and Midwifery Council 2015, Nursing Council of New Zealand), There is now a well-documented evidence base indicating that these priorities are often ignored, forgotten or overridden (Reader \& Gillespie, 2013). This may be a consequence of committed and competent staff trying to manage competing priorities under very difficult circumstances. It may also be an outcome of errors, omissions or mistakes. This does not however, account for all instances of care failure. The focus of this paper is poor care - a term we use to describe actions or omissions by health care staff that involve deliberate neglect, abuse, or incompetence, systemic and personnel failures or toxic/confounding combinations of the aforementioned. It may or may not lead to serious or even fatal consequences for patients. Where errors, mistakes and episodes of missed care may lead to the same serious outcomes, we distinguish them from poor care in that the former are unintentional actions which are a result of human or organizational factors (Ion, Jones, \& Craven, 2016). To further clarify, our interest here is in what might be called failures of health care humanity where, for example, patients are ignored, left unkempt or uncared for, neglected or otherwise treated as unimportant. What we have termed 'poor care, others have more bluntly described as 'shitty nursing' (Richards \& Borglin, 2018).

\section{Bystanders to poor care}

As well as formal legal sanctions, national nursing organisations have mechanisms for judging and sanctioning those who are found to have directly participated in neglect, abuse or incompetent care. In the UK for example, the primary role of the Nursing and Midwifery 
Failure to report as a breach of moral and professional expectation

Council (NMC) is the protection of the public, with its Fitness to Practice panel holding the ultimate sanction of removal of a registrant's right to practice. While there may be few contentious issues concerning the disciplinary consequences for those who are judged to have directly contributed to poor care, the position and culpability of those who are witness to these cases is sometimes less clear. Our focus here is on these witnesses or bystanders. We consider the explanations proffered for why some who directly observe poor care decide to raise their concerns, while also exploring accounts explaining why others choose to ignore them. We examine legal, professional and ethical guidance for health workers and the implications of not reporting, both for the patient and the nurse. Finally, we reflect upon the steps that might be taken to address the problem of those professionals, at whatever organisational level, who remain passive when faced with neglect, abuse or incompetence. Our overarching thesis is that both from the perspective of deontological ethical theory (the ethics of duty and obligation) and from consequential and virtue ethics perspectives, registrants who witness poor care ought to take action when they encounter it. To do otherwise is a breach of professional and ethical guidance that in some cases may also contravene national legislation. It is also, quite simply, morally wrong.

\section{Is poor care a significant problem?}

There is good evidence to suggest that this is a significant problem. It is a global issue and appears to be becoming more commonplace, if not 'the new normal' as some suggest (Richards \& Borglin 2018, p.2). Nursing care is particularly implicated in many of these notorious cases. It is now ten years since the explosive depictions of the appalling 'care' and neglect 
Failure to report as a breach of moral and professional expectation

experienced by predominant elderly people in the NHS detailed in the Patients' Association report: ‘Patients not numbers: People not statistics' (The Patients’ Association, 2009). It is six years since the scale of care failure at Mid Staffordshire NHS Trust in the UK became apparent with the publication of the Francis Report (Francis, 2013). This was quickly followed by revelations of failure at the Vale of Leven (MacLean, 2014), at Winterbourne View (Phelvin, 2014), Morecambe Bay (Walsh, 2013) and in Wales (Andrews \& Butler, 2014). Health care and the state of professional caring in the UK is under significant scrutiny, with nursing care particularly implicated (Traynor \& Buus, 2016). In 2018 a possible new nadir was reached with publication of the 'Gosport Report' in the UK detailing the possible 'shortening of the lives' of some 600 or more older people in a hospital (Darbyshire \& Ion 2018, Darbyshire \& Ion 2019)

Poor care is not however a purely British phenomenon. Malmedal, Hammervold, and Saveman (2014) have shown that abuse, neglect and inadequate care are realities for patients in many countries - a claim borne out by Hindle, et al. (2006) in their analysis of eight inquiries across six countries. In a more recent review of patient neglect in health care settings, Reader and Gillespie (2013) noted widespread public concern around the issue in both Europe and North America, reporting on evidence of its occurrence across these continents, as well as in Asia and Africa. It may be tempting to argue that this is a recent phenomenon and evidence of a modern malaise in the health care professions. This would be to ignore the historical record which clearly indicates that abuse and neglect of patients has always been with us (Ion \& Beer, 2003, Ryden-Grange, 2015). It would be similarly incorrect to think that the poor care problem has been resolved in the wake of the fallout from previous scandals. In an interview in February 2017, Sir Robert Francis made it clear that he felt another failure on the scale of MidStaffordshire was now inevitable in the UK health system (Ford \& Lintern, 2017). Similarly in 
Failure to report as a breach of moral and professional expectation

Australia another scandal has recently unfolded at Oakden ‘care facility’ for older people with dementia and other mental health issues, where the official report subtitled, 'A Shameful Chapter in South Australia's History' describes the situation, somewhat predictably, as one which should never have happened and must never happen again in the future (Lander, 2018).

\section{Reporting poor care: how do witnesses respond?}

In the wake of the events at Mid Staffordshire (Francis, 2013), there was critical debate in the literature about the extent to which bystanders were fully aware of the degree to which standards were compromised. Two related lines of argument were put forward. First, that contextual factors, including the pressure of the work environment, may have meant that some staff simply did not notice what should otherwise been apparent (Paley, 2014) and second, that continued exposure to poor care might have inured some to the reality of the situation (Timmins \& De Vries, 2014). It may be hard to comprehend, but , if nurses are unaware of poor care or are unable to identify it, then we cannot expect them to respond. Although work may need to be done to address the circumstances which affect the ability to recognise transgressions, our focus here is on those who are aware that abuse, neglect or incompetence have compromised patient safety.

Numerous researchers and commentators have examined this topic. Jackson et al. (2014) reviewed the empirical work which explores the responses of registered nurses to poor practice, with Milligan et al. (2017) Ion, Smith and Dickens (2017), Bickhoff, Levett-Jones, and Sinclair, (2016) and Fagan, Parker, and Jackson, (2016) undertaking similar work in relation to nursing students. They reach the same general conclusions. First, those who witness poor 
Failure to report as a breach of moral and professional expectation

care and report it tend to do so because of their personal moral position and / or a commitment to professional standards. Here the act of addressing poor practice is often framed as personally and professionally challenging and may require what Bickhoff et al.(2016) describe as moral courage. Second and crucially for this paper, it is clear that many of those registrants and students who witness poor care do not report it. In the main this is because they fear a range of negative personal and professional consequences that may befall them if they 'whistleblow'. Examples might include: bullying, ostracism by co-workers and negative impact on future career prospects . Some also choose to ignore the problem because they believe that their intervention is unlikely to make any tangible positive difference to the situation. There is a well-developed social psychological literature on the subject of excuse-making and exoneration, which is broadly reflective of these findings (Antaki, 1994). This argues that decisions to privilege self over others is frequently justified though the development of arguments or excuses which position the individual facing an ethical dilemma as having little or no choice in terms of how to respond. It is suggested that the potential negative consequences of action are so great that inaction, or in this case non - reporting of poor care, is the only reasonable course open to the witness and moreover, this is the same inaction that most reasonable people would take under the same conditions. According to Ion et al. (2016) accounts of this type serve to protect the individual both from cognitive dissonance and from the potentially negative evaluations of others, which might be expected to occur by placing self before patient.

The outcome of much of this work has been a general acceptance of the very real difficulties associated with whistleblowing and an acknowledgment that the decision to keep quiet in the face of poor practice may be 'understandable', or at least the only reasonable option open in many cases. Duffy et al. (2012) for example, asked if we may be expecting too much of nursing 
Failure to report as a breach of moral and professional expectation

students by expecting them to raise their concerns, while Glasper (2015) has talked of the support that must be provided if challenging poor practice is to be a reasonable option. The motives or moral integrity of such authors is not in question, but it is possible that repeated insistence on the difficulty of reporting may inadvertently perpetuate a culture of avoidance. It could be argued that this position is further sustained in some of the official reports and professional commentaries that have been written on the topic and that highlight the challenges of raising concerns. Francis' (2015) grim account of whistleblowing in the UK health service may be an example, as is the recent report from the UK House of Commons Public Administration and Constitutional Affairs Committee (2017), which details the UK Health Services’ poor record on investigating and handling complaints, exasperatingly entitled: "Will the NHS Never learn?”

While this 'it's difficult' stance seems to the dominant position, it has been questioned by some commentators. In their discourse analysis of student nurses’ accounts of actions and omissions in relation to reporting poor care, Ion et al. (2016) suggested that credence be given to the idea that perhaps nurses who witness poor care and do not report it are opting to privilege self, in preference to protecting the patient by directly tackling instances of poor care. Arguing for the continued relevance of moral character and individual accountability Darbyshire, Ralph, and Caudle, (2015) have also been critical of those who have tried to remove all responsibility from the individual in order to place it within a depersonalised system or situation. Roberts, (2016, 2017) has also explored the issue of personal responsibility and poor care. Drawing on Sartre's concept of 'bad faith' and his position on individual freedom, he argues that, while reporting poor care may be an uncomfortable or even very unpleasant experience, it is disingenuous for individuals to claim that they were unable to do so. In preference to the deterministic position taken by those who maintain that whistleblowing is often too dangerous 
Failure to report as a breach of moral and professional expectation

to consider, following Sartre, Roberts, takes the view that we are fundamentally free to choose what we do, or do not do. By extension, if we opt to turn a blind eye to the occurrence of bad practice, we do so freely and not because we had no other option. In summary then, although it has become commonplace to argue that a failure to report poor care is understandable and as such excusable, there is a developing literature which questions this view and which foregrounds the position that nurses are professionally, morally and legally bound to challenge care which is harmful, regardless of their personal concerns about doing so.

\section{Failure to act and its potential consequences}

For staff who witness poor care, there are undoubtedly 'benefits' to be gained from deciding those who spoke up had been ostracised and become unwell as a consequence, as well as cases where the impact of their actions had spilled over into family life. Francis (2015) was equally clear that the negative consequences for the individual of doing the right thing could to ignore it. These are predominantly the avoidance of potentially negative consequences. In their review of the whistleblowing literature, Jackson et al. (2014) identified situations where be very significant. An awareness of these potentially adverse consequences is also clear in some of the empirical work on student encounters with poor care which was reviewed by Ion, Smith and Dickens (2017). Sadly such fears are well-founded as the literature on the negative effects of whistleblowing on the whistleblower shows (Wilkes et al. 2011).

The evidence that negative outcomes always arise and that when they do they are invariably significant for those who raise concerns is less clear. This is particularly in cases where poor care is challenged less formally (Jones \& Kelly, 2014) or when the culture in which reporting takes place is supportive (Levett-Jones \& Lathlean, 2009). In situations of this type, the 
Failure to report as a breach of moral and professional expectation

consequences for reporters may even be positive. Moreover, work with student nurses has indicated that some of those who report do so out of a sense of moral or professional commitment. Presumably in these instances, there is the possibility that reporting has positive psychological outcomes insofar as action taken is complementary to the individual's own ethical compass (Ion et al. 2016).

For patients, the failure on the part of health workers to take action has no known positive outcomes, only a wide range of negative ones. Given the evidence that that much poor care goes unreported, it is difficult to quantify the full scale of human misery associated with professional inaction. We do, however, know what the consequences of poor care are and can therefore conclude that failure to report it is likely to perpetuate suffering. Although profound, the reporting of mortality statistics alone does not necessarily capture the full nature of patient suffering caused by poor care. A clearer view of this is provided by Reader and Gillespie (2013) in their review of patient neglect in healthcare. They identified examples of rudeness and failure to meet patient hygiene and pain relief needs in two South African obstetric units (Jewkes, Abrahams, \& Mvo, 1998), failure to assist bedridden patients in German homes (Goergen, 2004), the ignoring of patients and allowing unnecessary delays in attending to their needs in Norwegian nursing homes (Malmedal, Ingebrigtsen, \& Saveman, 2009) and failure to provide adequate nutrition and hydration in American nursing homes (Zhang et al., 2011) Further examples can be found in Masala-Chockwe and Ramukumba, (2015) and Chokwe and Wright (2011) whose work with student midwives in South Africa revealed examples of registrants ignoring patients cultural preferences, 'screaming' at a patient in the operating theatre, sleeping while on duty and failing to provide emotional support to a women whose baby had died before birth. A similarly stark picture of the impact of poor care is provided in the UK Parliamentary 
Failure to report as a breach of moral and professional expectation

and Health Service Ombudsman's report (Health Service Ombudsman, 2011) that detailed ten cases of care failure across the English NHS, quoting one relative as saying:

Our dad was not treated as a capable man in ill health, but as someone whom staff could not have cared less whether he lived or died (p.1).

That the life of a loved one could appear to be of so little value to those charged with their care is profoundly troubling. Perhaps most disturbing of all is the evidence that has emerged over recent years regarding the involvement of American medical and nursing personnel in the torture and degradation of enemy combatants in Iraq, Afghanistan and at Guantanamo. Mohr's (2009) chilling summary makes very discomforting reading:

... 60 years after the Nuremberg trials, America's healthcare professions are faced with the knowledge that their members have been complicit with abetting torture and concealing evidence or remaining silent about brutalization of human beings in their care (p. 289).

Put simply, while the failure to raise concerns may be understandable regarding any disruption of the status quo of the health professional's life, the potential consequences for patients may be catastrophic. There is a clear tension here between the needs of the health care worker as a person and the needs of the vulnerable people for whom they provide care. There is a similar dissonance between the health worker as a person and their professional position.

\section{Ethical practice and the expectation that nurse will protect the vulnerable}

Health care workers are subject to a range of legal, ethical and moral frameworks which dictate, guide and suggest how they should respond when faced with difficult decisions or 
Failure to report as a breach of moral and professional expectation

circumstances. Here we consider these in light of the problem of what to do when faced with evidence of incompetent care, abuse or neglect of patients.

Practitioners are subject to the laws of the country in which they work. At the extreme end of the spectrum, poor care may overlap with criminal activity, for example in cases of patient abuse. It is possible therefore that a member of staff who witnesses, or is aware of, financial, physical, psychological or sexual abuse of a patient may breach the laws of that country if they choose to ignore the action. In doing this they invite legal sanction. From a professional perspective, guidance provided by regulatory bodies invariably makes it clear that staff have a duty to respond to and raise their concerns if they are concerned about patient welfare. For example, section four of the Code of Ethics of the International Council of Nurses (ICN, 2012) states that the nurse must take:

....appropriate action to safeguard individuals, families and communities when their health is endangered by a co-worker or any other person.

There is no ambiguity here and it is clear that a nurse who fails to act is in breach of this guidance. An expectation that the registrant will take action is also made clear in the Nursing and Midwifery Board for Australia’s (2018) Code of Conduct for Nurses in which Principle 2 makes it clear that nurses must act upon concerns about patient safety. In the UK, a similar position is made explicit in the Code (NMC 2015), which states that registered nurses must

... work within the limits of your competence, exercising your professional 'duty of candour' and raising concerns immediately whenever you come across situations that put patients or public safety at risk. 
Failure to report as a breach of moral and professional expectation

This guidance makes it clear that patient safety is paramount and that there is an expectation that concerns about poor care will be addressed proactively. To conclude that behaving otherwise might be either negotiable or discretionary is wrong. Failure to address poor care is a direct breach of standards which puts the witness of such abuse, neglect or incompetence at odds with the expectations of regulators and may incur professional sanction.

Health care has sought guidance from a range of ethical and moral frameworks to help consider the way to best respond to difficult situations and dilemmas which arise in work with vulnerable people (Edwards, 2009). These invariably draw on Anglo-European traditions such as deontological, utilitarian/consequential, virtue or principle-based approaches. With the exception of utilitarian/consequence based systems where it might be possible to construct an argument that a greater good could be served by privileging the needs of the many over the individual, these principles offer little room for doubt when applied to the problem of how to respond to poor care. Applying Kant's categorical imperative, often interpreted as 'do unto others as you would have them do unto you' (Edwards, 2009, p. 838), it is hard to see a case which allows for inaction in the face of abusive, negligent or incompetent care. Similarly in virtue ethics, where for nurses virtue is commonly taken to mean behaviour which is aligned with kindness, care, sensitivity and courage, it seems very unlikely that nurses could legitimately argue that allowing the continuation of preventable distress through the failure to intervene is a legitimate course of action. The same conclusions are reached when an answer to the problem of poor care is sought through application of Beauchamp and Childress (2013) principles of beneficence, non-maleficence, justice and autonomy. Commonly interpreted as do good, do no harm, act fairly and respect the rights of the person, the health worker who is witness too, but ignores poor care, is clearly at risk of breaching one or more of these (Gamble \& Ion, 2017). 
Failure to report as a breach of moral and professional expectation

\section{Responding to the challenge}

Poor care is an unpleasant reality that results in significant suffering. Legal, professional and ethical guidance is unequivocal in relation to expectations about the behaviour of registrants who witness it. We now explore what might be done to address the phenomenon of the passive bystander who witnesses abuse, neglect or incompetence but chooses to ignore it. Our focus here is on moral courage - the idea that individuals will act in the face of possible risk to self if they believe that there is a 'right' course of action that must be followed to achieve a greater good. Before doing this we wish to emphasise that moral courage is only one element in the reporting of poor care. Of equal and perhaps greater significance are the cultural norms and values which prevail in health systems. We include not only organizational culture and leadership style but also the relationships between employers, employees and professional bodies and trades unions. Where these are open, transparent, insistent on hearing 'bad news' as well as 'good news', where they expect and value feedback, reward professional engagement and value partnership over adversarial approaches, then individuals must step up and speak out. There is no acceptable excuse for not doing so. However, if the environment is toxic, honest dialogue becomes impossible and thus only the very courageous will speak out. As Hindle et al. (2006) noted, reliance on ‘personal heroism' alone is woefully insufficient and indicative of a system or organisation that is morally bankrupt. Such a system seems to tacitly accept that poor care is an inevitable part of the 'norm' as are the malevolent power plays that would readily silence all but the most 'heroic' of whistleblowers. It is almost impossible to see any aspect of such a system that is acceptable today. Put bluntly, if your staff must be 'personally heroic' in the face of systemic toxicity as they report poor care, there are not merely some 'bad apples' but a rotten and poisonous orchard (Darbyshire \& Thomson 2018, p.142). Our discussion here is focused on what can be done by ordinary nurses in environments where 
Failure to report as a breach of moral and professional expectation

speaking out may at times be uncomfortable or even difficult, it is not concerned with situations where only a hero would take a risk. We consider three questions. First we ask if we can be confident that those who enter the profession fully understand the responsibilities they have committed to when doing so? It would be unreasonable to expect individuals to act against self-interest if they have no sense that this might be a requirement of the role at the earliest point possible. Second we consider whether or not we can be confident that all nurses fully understand the ethical frameworks upon which the profession is built. Without this we are expecting individuals to make difficult choices and decisions based upon experiences and knowledge gained outside the discipline and we cannot be certain that this alone will suffice. Finally we consider the issue of action and what might be done to develop and activate individual moral courage.

According to Cabaniss (2011), popular conceptions of the profession are often outdated and frequently depict an image that harks back to a non-existent halcyon past in which selfless young women assisted heroic male physicians. A recent review of twenty-one studies by Girvin, Jackson, and Hutchinson (2016) found similar misconceptions about the work of nurses, which were also echoed by Tuckett, Kim, and Huh (2017) and Glerean et al. (2017). If as seems likely, applicants draw on this pool of cultural information when considering entry to the profession, it is hardly surprising that they may feel overwhelmed when faced with the reality of clinical work. If the profession expects those who enter to fully understand the nature of the work and the personal commitment it requires, then it needs to take steps to ensure this. There are some simple messages which can be conveyed in both recruitment campaigns and more generally when presenting the work of nurses. While it can be tremendously rewarding and provides many opportunities, nursing is hard, nursing is difficult and it requires skill alongside personal qualities such as kindness, trustworthiness, fierce intelligence and at times, 
Failure to report as a breach of moral and professional expectation

moral courage. In addition nurses need intelligence, a sense of curiosity, an eye for detail and a commitment to what is often denigrated as 'basic care', but which would be better framed, as it is through the eyes of patients, as essential or fundamental care. It is rarely if ever glamorous - how could it be otherwise when it involves supporting the troubled, the sick, the dying and the bereaved? It is challenging and assuredly places a burden on the individual. Part of this burden is the heavy responsibility that cannot be sloughed off, for the care of others, which comes with professional registration. Those who understand and accept this may be better equipped to deal with the fallout that can sometimes result when taking action to protect the vulnerable.

Having a realistic understanding of the work may help to some extent, but is not on its own sufficient to equip practitioners with the knowledge and skills they need to respond to concerns about care provision. Although individual moral frameworks are developed in a variety of ways across a lifetime, there is a clear need for educators and employers to provide robust ethics and indeed 'political' (small 'p') education which adequately prepares nurses to deal with ethical dilemmas, such as the reporting of poor care within the complex systems in which many will work. The extent to which this happens is unclear (Ion, De Souza \& Kerin,2018). While professional bodies are invariably explicit that education providers must address ethical issues in their programmes, the manner in which this is done is left to the institution. This in turn may be dependent on the interests and inclinations of individual faculty. This suggests that there may be room to strengthen the ethics component of many undergraduate and continuing professional development programmes, not least by more tangibly integrating the "real worlds" of clinical practice with ethical theory and philosophy. Woods, (2005) for example, argued over ten years ago that ethics education for nurses may not be fit for purpose and in doing so called for nurse academics to review their teaching approaches. Work by Grady et al. (2008) also found that exposure to ethics education amongst American nurses and social workers was 
Failure to report as a breach of moral and professional expectation

variable. Of equal importance they found who those had received it were both more confident and more likely to take moral action. Robinson et al. (2014) similarly reported that enhanced applied approaches to ethics teaching can have a positive impact on behaviour in the practice setting - specifically, that participants felt more able to respond to ethical challenges, including unethical practice by others. More recently Chao et al. (2017) demonstrated that ethical decision making competence amongst student nurses could be improved using a web-based teaching package. In summary there is evidence to indicate that ethics education should be strengthened and that when this occurs, carefully designed interventions can have a positive impact on both knowledge and action in the field. Educators need to review their approaches to ensure that students are fully prepared for the challenges presented by clinical practice. Unless we can be certain that this is the case, it is simply wishful thinking to trust that they will always respond appropriately when they encounter difficulties.

We now turn to the issue of moral courage, but before doing so we again wish to reiterate that we oppose simplistic exhortations to 'be courageous' in situations which invite personal catastrophe. Our interest here is in making a case for the value of courage in situations which may be difficult, but which are certainly not impossible. For Hamric, Arras, \& Mohrmann (2015) three conditions need to be met before an action can be considered to be morally courageous. First it needs to involve some degree of risk to the person - action in the absence of risk may demonstrate any number of qualities, but does not require moral courage. Second, the action must be directed toward some desired social good. Without this it may be brave, but cannot be an example of moral courage. Third the actor must have thought through the potential consequences of their actions and determined that, despite the risk, intervention is required. This later point distinguishes courage from reaction in the heat of the moment. This final point is dependent upon the person being able to think through and consider a range of issues and 
Failure to report as a breach of moral and professional expectation

evaluate the consequences of choosing a specific course. The ability to think critically is a key component of this process. In their recent systematic review of teaching methods used to develop critical thinking Yoe et al. (2017) argued for the importance of this skill, but noted that while discussion is not in short supply, there is relatively little empirical evidence to guide our teaching in terms of how best to develop this attribute. What we know minimally is that methods which directly engage learners in the evaluation of actions and the making of decisions seems to hold some promise. At the very least, educators need to review the emphasis they place on this skill and ensure that it is robustly addressed in preparatory programmes.

According to Gallagher (2011) moral courage is facilitated by practice. More specifically, courage is more likely to occur if we become habituated to using it. The issue here for educators and clinicians is to create opportunities for students and registered nurses to speak up, to challenge, debate, discuss and argue across curricula (DeSimone, 2019). This may be difficult in a profession which has traditionally valued conformity and deference over perceived expertise. This difficulty may be even more marked in a clinical world which seems to value the chimerical certainty of checklists and assessed competencies above all else. It may require a different approach to teaching and learning for many educational institutions - Goodman’s (2013) comments on instrumentalism in nurse education are worth considering here - but if today's students cannot do this in the classroom, it is highly unlikely they will consider doing so in the practice setting.

Finally we turn to the issue of leadership and moral courage. Change may be glacially slow unless the profession's senior leaders in both practice and education grasp the problem and 
Failure to report as a breach of moral and professional expectation

commit to making progress (Edmondson 2015). Writing about the unethical treatment of prisoners from the 'War on Terror', Wocial, (2009) stated that:

Nurse leaders must break their silence and speak out against the active or passive mistreatment of all members of the human family. (p. 294).

Mohr (2009) is equally clear in her assertion that nurse leaders must be unequivocal about their expectations of professionals. This must also be accompanied by an open debate which accepts the problem of poor care and nurses involvement in it, but which also makes a commitment to making the structural changes which have allowed it to flourish, such as the acceptance of a culture of silence. For example, MaCurtain et al. (2018), recently emphasised the importance of the leader in encouraging bystanders to intervene in situation where colleagues are being bullied. Leaders too are human beings who may be subject to the same degree of professional censure from their 'superiors' for speaking up, as are the most junior of student nurses. If they have been chosen wisely however, they should be fully aware of the expectations of their roles, one of which is to lead by example. There is nowhere for ANY health professional to hide in this crucible of poor care.

\section{Conclusion}

Poor care is a threat to patient safety and dignity and damages the integrity of our profession. Concern about poor care has been reported in health services across the world. Evidence indicates that it sometimes goes unreported and that suffering results as a consequence. Legal, professional and ethical guidance make it clear that nurses have a duty to take action when they encounter it. Work to date has focused on exploring why care failure occurs, with scant discussion about the obligations of those who witness it. We argue that the witness to poor care 
Failure to report as a breach of moral and professional expectation

risks legal as well as professional sanctions if they remain passive and 'look the other way'. Critically, failure to act in the face of abuse, neglect or incompetence leaves the witness in breach of all commonly accepted ethical guidance on how to respond when faced with moral dilemmas.

The likelihood of more proactive responses may be increased by ensuring that those who enter the profession understand the responsibilities of the registrant, by the provision of applied education which directly addresses the problems faced by those who encounter ethical dilemmas in the practice setting and by steps to develop and activate individual moral courage. Significant change in the poor care landscape is only likely to take place where practice cultures truly desire and welcome feedback and promote critical reflection around patient safety, dignity and care quality and where this cultural and professional bedrock actively and passionately supported by those in leadership positions. The price of failure here for nursing and healthcare is simply too terrible to contemplate. 
Failure to report as a breach of moral and professional expectation

\section{References}

American Nurses Association. (2015). American Nurses Association code of ethics: Revised version 2015.

https://www.nursingworld.org/practice-policy/nursing-excellence/ethics/code-of-ethics-fornurses/

Andrews, J., \& Butler, M. (2014). Trusted to care an independent review of the Princess of Wales Hospital and Neath Port Talbot Hospital at Abertawe Bro Morgannwg University Health Board. Development Services Dementia Centre.

https://gweddill.gov.wales/docs/dhss/publications/140512trustedtocareen.pdf

Antaki, C. (1994). Explaining and arguing: The social organization of accounts. London: Sage.

Bagnasco, A., Timmins, F., de Vries, Jan M A, Aleo, G., Zanini, M., Catania, G., \& Sasso (2017). Understanding and addressing missed care in clinical placements implications for nursing students and nurse educators. Nurse Education Today, 56, 1-5. https://doi.org/ 10.1016/j.nedt.2017.05.015

Beauchamp,.L, \& Childress, J.F. (2013). Principles of biomedical ethics. 7th edition. Oxford: 
Failure to report as a breach of moral and professional expectation

Oxford University Press.

Bickhoff, L., Levett-Jones, T., \& Sinclair, P. M. (2016). Rocking the boat: nursing students' stories of moral courage: A qualitative descriptive study. Nurse Education Today, 42, 35-40. https://doi.org:10.1016/j.nedt.2016.03.030

Cabaniss, R. (2011). Educating nurses to impact change in nursing's image. Teaching and Learning in Nursing, 6 (3), 112-118. https://doi.org/10.1016/j.teln.2011.01.003

Chao, S. Chang, Y. Yang, S. C., \& Clark, M. J. (2017). Development, implementation, and effects of an integrated web-based teaching model in a nursing ethics course. Nurse Education Today, 55, 31-37. https://doi.org/10.1016/j.nedt.2017.04.011

Chokwe, M., \& Wright, S. (2011). Caring in clinical practice: Experiences and perceptions of learner midwives. Evidence Based Midwifery, 9 (4), 125-130.

Darbyshire, P. and Ion, R. (2018) The lessons of Gosport for nursing education. Nurse Education Today , 70 , 130-135 https://doi.org/10.1016/j.nedt.2018.08.018 
Failure to report as a breach of moral and professional expectation

Darbyshire, P. and Ion, R. (2019) The Gosport War Memorial Hospital Panel report and its implications for nursing. Journal of Advanced Nursing, 75(2), 258-263.

https://doi.org/10.1111/jan.13781

Darbyshire, P., Ralph, N., \& Caudle, H. (2015). Editorial: Nursing's mandate to redefine the sentinel event. Journal of Clinical Nursing, 24, 1445-1446, https://doi.org/10.1111/jocn.12840

Darbyshire, P. and Thompson, D. (2018) Gosport must be a tipping point for professional hierarchies in healthcare_-an essay by Philip Darbyshire and David Thompson. BMJ : British Medical Journal (Online), 363. https://doi.org/10.1136/bmj.k4270

DeSimone, B.B. (2019) 'Curriculum Redesign to Build the Moral Courage Values of Accelerated Bachelor’s Degree Nursing Students. Open Nursing, 5, 1-10 https://doi.org/10.1177/2377960819827086

Duffy, K., McCallum, J., Ness, V., \& Price, L. (2012). Whistleblowing and student nurses are we asking too much? Nurse Education in Practice, 12 (4), 177-178.

https://doi.org/10.1016/j.nepr.2012.04.002

Edwards, S. D. (2009). Nursing ethics: A principle-based approach. 2nd edition. London, Palgrave MacMillan. 
Failure to report as a breach of moral and professional expectation

Fagan, A., Parker, V., \& Jackson, D. (2016). A concept analysis of undergraduate nursing students speaking up for patient safety in the patient care environment. Journal of Advanced Nursing, 72(10), 2346-2357. https://doi.org/10.1111/jan.13028

Ford, S., \& Lintern, S. (2017). Sir Robert Francis warns current NHS pressures make another mid staffs 'inevitable'. Nursing Times, 113 (2), 1-3.

Francis, R. (2015). Freedom to speak up: An independent review into creating an open an honest reporting culture in the NHS. Available online http://freedomtospeakup.org.uk/wp-content/uploads/2014/07/F2SU_web.pdf Francis, R. (2013). Report of the Mid Staffordshire NHS foundation trust public inquiry. . The Stationary Office, England). London: Stationary Office.

https://www.gov.uk/government/publications/report-of-the-mid-staffordshire-nhs-foundationtrust-public-inquiry

Gallagher, A. (2011). Moral distress and moral courage in everyday nursing practice.

Online Journal of Issues in Nursing, 16 (2), 1.

https://doi-org.libproxy.abertay.ac.uk/10.3912/OJIN.Vol16No02PPT03 
Failure to report as a breach of moral and professional expectation

Gamble, C. (2017). Poor care and the professional duty of the registered nurse. Nursing

Older People, 29(4), 20-24. http://doi:10.7748/nop.2017.e908

Girvin, J., Jackson, D., \& Hutchinson, M. (2016). Contemporary public perceptions of nursing: A systematic review and narrative synthesis of the international research evidence.

Journal of Nursing Management, 24 (8), 994-1006. https://doi.org/10.1111/jonm.12413

Glasper, A. (2015). Protecting students who raise concerns about care delivery. British Journal of Nursing, 24 (10), 544-545. https://doi.org/10.12968/bjon.2015.24.10.544

Glerean, N., Hupli, M., Talman, K., \& Haavisto, E. (2017). Young peoples' perceptions of the nursing profession: An integrative review. Nurse Education Today, 57, 95-102.

https://doi.org/10.1016/j.nedt.2017.07.008

Goergen, T. (2004). A multi-method study on elder abuse and neglect in nursing homes. Journal of Adult Protection, 6 (3), 15-25. https://doi.org/10.1108/14668203200400016

Goodman, B. (2013). “What are nurse academics for?” intellectual craftsmanship in an age of instrumentalism. Nurse Education Today, 33 (2), 87-89.

https://doi.org/10.1016/j.nedt.2012.08.015 
Failure to report as a breach of moral and professional expectation

Grady, C., Danis, M., Soeken, K. L., O'Donnell, P., Taylor, C., Farrar, A., \& Ulrich, C. M (2008). Does ethics education influence the moral action of practicing nurses and social workers? American Journal of Bioethics, 8 (4), 4-11.

https://doi.org/10.1080/15265160802166017

Hamric, A. B., Arras, J. D., \& Mohrmann, M. E. (2015). Must we be courageous? Hastings Center Report, 45 (3), 33-40. https://doi.org/10.1002/hast.449

Health Service Ombudsman. (2011). Care and compassion: Report of the health service ombudsman on ten investigations into care of older people. London : The Stationary Office https://assets.publishing.service.gov.uk/government/uploads/system/uploads/attachment_data /file/247493/0778.pdf

Hindle, D., Braithwaite, J., Travaglia, J., \& Ledema, R. (2006). Patient safety: A comparative analysis of eight inquiries in six countries.University of New South Wales: Clinical Excellence Commission http://www.cec.health.nsw.gov.au/__data/assets/pdf_file/0009/258273/patient-safetyreport.pdf 
Failure to report as a breach of moral and professional expectation

the NHS never learn? Follow-up to PHSO report 'Learning from Mistakes' on the NHS in England. London, House of Commons.

https://publications.parliament.uk/pa/cm201617/cmselect/cmpubadm/743/743.pdf

ICN. (2012). Code of ethics for nurses (2012) Geneva, ICN

https://www.icn.ch/sites/default/files/inline-

files/2012_ICN_Codeofethicsfornurses_\%20eng.pdf

Ion, R. M., \& Beer, M. D. (2003). Valuing the past: The importance of an understanding of the history of psychiatry for healthcare professionals, service users and carers. International Journal of Mental Health Nursing, 12 (4), 237-242.

https://doi.org/10.1046/j.1447-0349.2003.t01-1-.X

Ion, R., Jones, A., \& Craven, R. (2016). Raising concerns and reporting poor care in practice. Nursing Standard , 31(15), 55-63 doi:10.7748/ns.2016.e10665

Ion, R., Smith, K., \& Dickens, G. (2017). Nursing and midwifery students' encounters with poor clinical practice: A systematic review. Nurse Education in Practice, 23, 67-75. https://doi.org/10.1016/j.nepr.2017.02.010 
Failure to report as a breach of moral and professional expectation

Ion, R., Smith, K., Moir, J., \& Nimmo, S. (2016). Accounting for actions and omissions: A discourse analysis of student nurse accounts of responding to instances of poor care. Journal of Advanced Nursing, https://doi.org/10.1111/jan.12893

Jackson, D., Hickman, L. D., Hutchinson, M., Andrew, S., Smith, J., Potgieter, I. Peters, K. (2014). Whistleblowing: An integrative literature review of data-based studies involving nurses. Contemporary Nurse, 48(2), 240-252.

https://doi.org/10.1080/10376178.2014.11081946

Jewkes, R., Abrahams, N., \& Mvo, Z. (1998). Why do nurses abuse patients? Reflections from South African obstetric services. Social Science \& Medicine, 47(11), 1781-1795. https://doi.org/10.1016/S0277-9536(98)00240-8

Jones, A., \& Kelly, D. (2014). Whistle-blowing and workplace culture in older peoples' care: Qualitative insights from the healthcare and social care workforce. Sociology of Health \& Illness, 36(7), 986-1002. https://doi.org/10.1111/1467-9566.12137

Lander, B. (2018). Oakden: A shameful chapter in South Australia's history. Adelaide: ICAC. https://icac.sa.gov.au/system/files/ICAC_Report_Oakden.pdf

Levett-Jones, T., \& Lathlean, J. (2009). 'Don’t rock the boat’: Nursing students’ experiences 
Failure to report as a breach of moral and professional expectation

of conformity and compliance. Nurse Education Today, 29 (3), 342-349.

https://doi.org/10.1016/j.nedt.2008.10.009

MacLean, R. (2014). The Vale of Leven hospital inquiry report. Edinburgh Scottish

Government.

MacCurtain, S., Murphy, C., O'Sullivan, M., MacMahon, J. and Turner, T. (2018) To stand back or step in? Exploring the responses of employees who observe workplace bullying Nursing Inquiry, 25 (1) https://doi.org/10.1111/nin.12207

Malmedal, W., Ingebrigtsen, O., \& Saveman, B. (2009). Inadequate care in Norwegian nursing homes -- as reported by nursing staff. Scandinavian Journal of Caring Sciences, 23(2), 231-242. https://doi.org/10.1111/j.1471-6712.2008.00611.x

Malmedal, W., Hammervold, R., \& Saveman, B. (2014). The dark side of norwegian nursing homes: Factors influencing inadequate care. Journal of Adult Protection, 16 (3), 133-15. https://doi.org/10.1108/JAP-02-2013-0004

Masala-Chockwe, M., \& Ramukumba, T. (2015). Exploring the meaning of caring amongst student midwives, professional midwives and educators in Tshwane, South Africa. African Journal of Primary Health Care \& Family Medicine, 7, 1.

https://doi.org/10.4102/phcfm.v7i1.894 
Failure to report as a breach of moral and professional expectation

Milligan, F., Wareing, M., Preston-Shoot, M., Pappas, Y., Randhawa, G., \& Bhandol, J. (2017). Supporting nursing, midwifery and allied health professional students to raise concerns with the quality of care: A review of the research literature. Nurse Education

Today, 57, 29-39. https://doi.org/10.1016/j.nedt.2017.06.006

Mohr, W. K. (2009). Commentary: Fork in the road: Accessories to cruelty or courage?

Nursing Outlook, 57 (5), 289-291. https://doi.org/10.1016/j.outlook.2009.07.004

Nursing and Midwifery Board of Australia (2018). Nursing and midwifery board of Australia code of ethics for nurses.

https://www.nursingmidwiferyboard.gov.au/Codes-Guidelines-Statements/Professionalstandards.aspX

Nursing and Midwifery Council (2015).The Code: Professional standards of practice and behaviour for nurses and midwives.

https://www.nmc.org.uk/globalassets/sitedocuments/nmc-publications/nmc-code.pdf

Nursing Council of New Zealand (2012) Nursing Council of New Zealand code of conduct. http://www.nursingcouncil.org.nz/Nurses/Code-of-Conduct 
Failure to report as a breach of moral and professional expectation

Paley, J. (2015). Absent bystanders and cognitive dissonance: A comment on Timmins \& De-

Vries. Nurse Education Today. 35 (4) 543-548 https://doi.org/10.1016/j.nedt.2014.12.006

Phelvin, A. (2014). Winterbourne view hospital and the social psychology of abuse. Learning

Disability Practice. 17, 10, 25-29. https://doi:10.7748/ldp.17.10.25.e1581

Randall, D., \& McKeown, M. (2014) Failure to care: Nursing in a state of liquid modernity?

Journal of Clinical Nursing, 23(5-6), 766-767. https://doi.org/10.1111/jocn.12441

Reader, T. W., \& Gillespie, A. (2013). Patient neglect in healthcare institutions: A systematic review and conceptual model. BMC Health Services Research, 13, 156.

10.1186/1472-6963-13-156 [doi]

Richards, D.A. and Borglin, G. (2019) 'Shitty nursing' - The new normal? International Journal of Nursing Studies 91, 148-152. https://doi.org/10.1016/j.ijnurstu.2018.12.018

Roberts, M. (2016). Self-deception and poor patient care: A big idea from a Sartrean perspective. Nurse Education Today, 46, 1-3. https://doi.org/10.1016/j.nedt.2016.06.012 
Failure to report as a breach of moral and professional expectation

Roberts, M. (2017). A critical analysis of the failure of nurses to raise concerns about poor patient care. Nursing Philosophy 18 (3)

https://doi-org.libproxy.abertay.ac.uk/10.1111/nup.12149

Roberts, M., \& Ion, R. (2014). A critical consideration of systemic moral catastrophe in modern health care systems: A big idea from an Arendtian perspective. Nurse Education Today, 34 (5), 673-675.https://doi.org/10.1016/j.nedt.2014.01.012

Robinson, E. M., Lee, S. M., Zollfrank, A., Jurchak, M., Frost, D., \& Grace, P. (2014). Enhancing moral agency: Clinical ethics residency for nurses. Hastings Center Report, 44(5), 12-20. https://doi-org.libproxy.abertay.ac.uk/10.1002/hast.353

Ryden-Grange, M. (2015). 'What's psychology got to do with it?' Applying psychological theory to understanding failures in modern healthcare settings. Journal of Medical Ethics, 41(11), 880-884. https://jme.bmj.com/content/medethics/41/11/880.full.pdf

Stenhouse, R., Ion, R., Roxburgh, M., Devett, P.,F, \& Smith, S. (2016). Exploring the compassion deficit debate. Nurse Education Today, 39, 12-15.

https://doi.org/10.1016/j.nedt.2016.01.019

Traynor, M., \& Buus, N. (2016). Professional identity in nursing: UK students' explanations 
Failure to report as a breach of moral and professional expectation

for poor standards of care. Social Science \& Medicine, 166, 186.-194

https://doi.org/10.1016/j.socscimed.2016.08.024

Tuckett, A., Kim, H., \& Huh, J. (2017). Image and message: Recruiting the right nurses for the profession. A qualitative study. Nurse Education Today, 55, 77-81.

https://doi.org/10.1016/j.nedt.2017.05.007

Walsh, P. (2013). Morecambe Bay and the CQC. Clinical Risk, 19 (4), 96-97.

DOI $10.1177 / 1356262213502150$

Wilkes, L. M., Peters, K., Weaver, R., \& Jackson, D. (2011). Nurses involved in whistleblowing incidents: Sequelae for their families. Collegian, 18 (3), 101-106. https://doi.org/10.1016/j.colegn.2011.05.001

Wocial, L. (2009). Courage is the only ethical choice. Nursing Outlook, 57 (5), 294-295. https://doi.org/10.1016/j.outlook.2009.07.005

Woods, M. (2005). Nursing ethics education: Are we really delivering the good(s)? Nursing Ethics, 12 (1), 5-18.https://doi.org/10.1191/0969733005ne754oa

Zhang, Z., Schiamberg, L. B., Oehmke, J., Barboza, G. B., Griffore, R. J., Post, L. A., Mastin, 
Failure to report as a breach of moral and professional expectation

T. (2011). Neglect of older adults in Michigan nursing homes. Journal of Elder Abuse \& Neglect, 23 (1), 58-74. https://doi.org/10.1080/08946566.2011.534708 